\title{
INSERCIÓN DE LA MUJER EN EL MERCADO LABORAL EN LOS ALTOS CARGOS DIRECTIVOS EN EL SECTOR EDUCATIVO
}

\author{
Women senior managers in the Higher Education sector
}

\author{
Victoria Inés Pérez Cuello1 \\ María Natalia Huertas García ${ }^{1}$ \\ Amalfi Padilla Castilla²
}

RESUMEN

El presente artículo, hace alusión a la evolución del papel y desempeño de la mujer en sus roles ante la sociedad, contextualizando los acontecimientos que han logrado transformar cronológicamente, ciertos paradigmas, estereotipos sociales, culturales, políticos y económicos tanto a nivel internacional como nacional; haciendo énfasis en los acontecimientos relevantes para que se hiciera eficaz, la participación de la mujer en distintos ámbitos, independientes a la maternidad y la vida familiar, como es el caso de la primera mujer que ingresa como estudiante a la universidad colombiana. Gerda Westendorp fue admitida en 1935 en la Universidad Nacional de Colombia en la carrera de medicina, lo que representó un cambio frente a la apertura del conocimiento en un espacio excluyente y rígido. De igual forma este artículo de reflexión busca identificar la inserción progresiva de la mujer al mercado laboral, identificando las variables que intervienen y condicionan en la sociedad, tales como la formación académica, nivel educativo, salario y lo que realmente significa el techo de cristal o suelo pegajoso, que, a pesar de efectivamente ser obstáculo, que no permiten a la mujer avanzar en espacios significativos que a pesar de los años siguen siendo inmóviles e irrompibles

Palabras clave: Condición de género, Mercado laboral, Estereotipos sociales.

\footnotetext{
${ }^{1}$ Programa de Administración de Empresas de la Universidad de Cartagena, integrante del grupo de investigación Gestión del Conocimiento y Calidad educativa. E-mail: vickycuelloj@gmail.com; naticohuga@gmail.com

${ }^{2}$ Docente investigadora de la Universidad de Cartagena. Líder del grupo de investigación Gestión del Conocimiento y Calidad Educativa. PhD. Ciencias de la Educación
} 


\begin{abstract}
This article, refers to the evolving role and performance of women in their roles in society, contextualizing the events that have transformed chronologically, certain paradigms, social, cultural, political and economic both international and national stereotypes; emphasizing relevant to be made effective events, the participation of women in different fields, independent motherhood and family life, as in the case of the first woman admitted as a student to the Colombian university. Gerda Westendorp was $\mathrm{He}$ admitted in 1935 at the National University of Colombia in a medical career, representing a change from the opening of knowledge in an exclusive and rigid space. Similarly, this reflection article seeks to identify the gradual integration of women into the labor market, identifying the variables involved and condition in society, such as academic training, education, salary and what it really means the glass ceiling or sticky floor, that despite actually being an obstacle, which does not allow women to advance meaningful spaces that despite the years remain motionless and unbreakable.
\end{abstract}

Keywords: Gender condition, Labor market, Social stereotypes.

\title{
Introducción
}

La discriminación viene acompañando a la sociedad desde tiempos remotos. Así la historia la mujer ha enfrentado obstáculos que representan desvinculación y discriminación, en ámbitos sociales, económicos, ideológicos, políticos y laborales, lo que se refleja en una realidad problemática latente y globalizada, que ha incitado a la mujer a luchar por mejores condiciones educativas y laborales.

Teniendo en cuenta el desarrollo de la mujer en el espacio empresarial son pertinentes lo que hoy las caracterizan con un "alto grado de incertidumbre, escaso nivel de predicción, entornos altamente complejos, globalización, economías emergentes e interdependientes, mayor competencia mundial, tendencias más globales que locales y cambios demográficos y tecnológicos” (Lipman-Blumen, 2000), hecho que en la actualidad nos envuelve y que nos genera ansiedad acerca de los importantes y grandes retos que deberán asumir las empresas.

A todo esto, le sumamos lo que es la igualdad de género y su participación en un mundo empresarial, hablando de la mujer, que cada vez vemos este proceso de incursión, en altos cargos 
gerenciales, avanzando lentamente dejando de lado lo que más importa en una empresa, lograr a obtener mayores utilidades y la aplicación de técnicas que les permitan llegar al éxito.

En otro orden de ideas, también se puede determinar este proceso como demarca Constantinidis (2010), la existente Categorización Social, puesto que tanto hombres como mujeres tienen una óptica distinta de las cosas que suceden y por ello se ha condicionado la manera de como las personas se perciben unas a otras, sin embargo no se puede dejar de lado la capacidad que tienen las mujeres para lograr mantener el orden, hacer las cosas de la mejor manera lo que las lleva a ser muy eficientes, ya que tienen la capacidad de responder a varios estímulos, y con ello a imponer nuevas tendencias para hacer de todo lo que nos rodea un ambiente cómodo y apto para todos.

Con el paso del tiempo la mujer ha tenido un desarrollo progresivo en la lucha contra la discriminación, logrando cambios en la mentalidad de la sociedad tanto así que la exclusión que recibía está quedando en el pasado, pero aun hoy en día se presentan casos de este tipo.

No obstante, cabe señalar la fuerte influencia de la sociedad y las diversas culturas, ya que han sido estas las encargadas de establecer o implantar un modelo de géneros que figura en las diferencias y desigualdades de los mismos, cuando se debe reconocer estos como focos de atención para promover las transformaciones en las relaciones de géneros desiguales, en las imágenes que desvalorizan o subvaloran lo femenino, (Mora, Fritz y Valdez, 2006). Por lo que determinan que "Ante el desafío de promover la equidad de género, se hace visible que se debe implementar una política de género en que las intervenciones sean culturalmente sensibles (2). Es decir, consideren que las culturas son los contextos en que se promueven y llevan a cabo las acciones de desarrollo."

Sin embargo, dando un vistazo a los hechos que suceden en el mundo se puede señalar que "Hoy en día es verdad que la cifra es aún baja en México $\mathbf{6 . 8 \%}$, comparada con otros países como, por ejemplo, países como Suecia donde tienen un $\mathbf{2 7 . 3 \%}$ de mujeres en los consejos de administración, o Noruega donde representa un 40.1\%." señaló Griselda Hernández”. (REVISTA WEB CRONISTA, 09/06/2011 - MÉXICO). 
Paralelamente se muestra que, "por otro lado, la creciente entrada de mujeres al mercado laboral ha generado la necesidad de desarrollar políticas públicas de género, con el objetivo de modificar la desigualdad de oportunidades y trato entre hombres y mujeres. Dentro de los convenios y compromisos internacionales donde se reafirma la importancia de garantizar la igualdad de género en el ámbito laboral se cuentan: (1) Los convenios, recomendaciones internacionales y la Agenda de Trabajo Decente de la Organización Internacional del Trabajo (OIT); (2) Los Objetivos de Desarrollo del Milenio de las Naciones Unidas (ONU); (3) Las Conferencias Interamericanas de Ministros de Trabajo de la Organización de Estados Americanos (OEA); (4) El MERCOSUR; (5) La Convención para la eliminación de todas las formas de discriminación contra la mujer (CEDAW)". (Maurizio, 2010) /

\section{(Revista web americaeconomia.com, 27/08/2014).}

Ubicándonos en el panorama colombiano, alrededor de la historia, la mujer se involucró en ámbitos donde anteriormente no tenía espacio, lo cual generó, mejores opciones laborales. Este gran avance fue durante el gobierno del general Rojas Pinilla, donde las féminas reclaman el derecho a elegir y a ser elegidas, siendo el 1 de Diciembre de 1957,la primera vez en que la mujer ejerce el derecho al sufragio, convirtiéndose este en un hecho trascendental y emblemático, dado que desde ese entonces, años posteriores "la participación electoral femenina se reactivó en la elección de López Michelsen, en cuyo mandato se dictaron normas fundamentales de derechos de la mujer en la familia, eliminando la potestad marital y declarando la igualdad jurídica de los sexos. A partir de 1974, los distintos gobiernos empezaron a nombrar mujeres en altos cargos del poder ejecutivo, nacional y regional, primero como viceministras y luego en otros cargos de importancia como la Cancillería, siendo Colombia uno de los pocos países con este hecho"(Velásquez Toro, Magdala), lo que indica que nuestro país Colombia, a pesar de todos los eufemismos en lo que se encuentra sumergido, presenta avance respecto al tema igualdad de género, con relación a otros países de América Latina.

Estos hechos anteriormente mencionados, son tomados como el despertar del género femenino en el país, hoy día la realidad es otra en Colombia, la diferenciación laboral por género, se hace evidente en la organización formalmente organizada, que vincula más a hombres que a mujeres, puesto que una problemática social, como lo es el trabajo informal, fenómeno que afecta a ambos géneros, pero que prevalece más en las mujeres, dado que "Sin importar ciertas características individuales de las 
mujeres, como son la edad y la educación, están sometidas a mayores tasas de informalidad que los hombres" (Alvares Vos, Oriana).

En cuanto al sector de la educación superior, es preciso resaltar que ha sido un proceso tedioso y que progresivamente ha ido aumentado, pues han incursionado varias mujeres como líderes del organigrama ,dado a las ventajas que aparentemente se ven directamente relacionadas a la forma de dirigir de las mujeres, expertos definen el estilo de dirección de las mujeres como "abierto, no competitivo, innovador, con un firme sentido de la calidad, centrado en la persona, flexible, comunicativo y persuasivo" (Grimwood y Popplestone, 1993) es éste el país latinoamericano con la mayor proporción de mujeres en posiciones de dirección según las investigaciones de Maxfield (2005, 2007). Esto lo confirman los datos del PNUD (Programa de las Naciones Unidas para el Desarrollo) que muestran que "Colombia tiene un 38\% de mujeres en posiciones administrativas" (Cárdenas \& Durana, 2009).

De acuerdo a la investigación realizada por Ana María Araujo Peñate y Simón Nieto Vanegas, titulada "Una aproximación a la participación de la mujer en la dirección de la universidad: características y tendencias" efectuada a 24 universidades, donde el análisis de los resultados, de dicha investigación arrojaron que de las 24 universidades, 18 resultaron lideradas por hombres y 6 por mujeres donde el $75 \%$ de las rectorías de las universidades corresponde a hombres y el $25 \%$ a mujeres, demostrando que hay una tendencia de preferencia a los hombres para este tipo de cargos, pero no descarta la posibilidad, de la inserción de estas, y la posibilidad de que se incremente el número en los altos cargos directivos.

En referencia a la participación de la mujer en el ámbito educativo Colombia dio paso en la formación universitaria de la mujer en la tercera década del siglo xx, en la ciudad de Cartagena se encuentran, casos que demuestran que, a pesar del inherente estado de inequidad, que asume el ámbito laboral, específicamente en la dirigencia universitaria. Tal y lo muestra el artículo "mujer y poder: representaciones sociales. caso de Beatriz Bechara de Borge, primera rectora de la Universidad de Cartagena 1988-1990”, escrito por Dora Piñeres, muestra "la primera y única mujer que hasta hoy ha asumido la dirección de la primera institución universitaria del Caribe Colombiano, la Universidad de Cartagena, y recrea las representaciones sociales que se producen en el corto tiempo, que estuvo como 
rectora entre septiembre de 1988 a marzo de 1990”, este hecho asignado como un capítulo importante para la ciudad y para la universidad, dado que tradicionalmente este ámbito había estado hasta ese momento construido organizacionalmente, por hombres, pocos casos de rectorías femeninas, se habían conocido hasta entonces, opuesto a ello, el observatorio de universidades Colombianas, hoy día muestra la mayor inserción de la mujer, estadísticamente ha aumentado, pero en muy pocos casos, de la costa Colombiana.

El "techo de cristal o suelo pegajoso", catalogado así por los impedimentos aparentemente invisibles, que se le presentan a la mujer, en su carrera laboral, obstaculizando su progreso y avance, en la ciudad Cartagena de India, Roxana Segovia de Cabrales sabe que prepararse, es la mejor forma de sobrellevar la inequidad de género y más en su condición de discapacidad, que no representa un obstáculo para ella, pues ella misma se define como "Una mujer con experiencia administrativa, con gran capacidad de trabajo, capaz de afrontar situaciones de presión y tomar decisiones", por ende es importantes estudiar y analizar los retos que ha asumido cumplir al ser rectora de la Universidad Jorge Tadeo Lozano ,por tanto es relevante ahondar en esta investigación, principalmente en este cargo, que ha desempeñado como rectora, apartando los tantos que ésta ha asumido, a través de su vida profesional, por lo significativo para el país y para la ciudad, el ámbito de los altos cargos directivos y la dirigencia universitaria, excluyendo la diferenciación de género.

A lo largo de las últimas décadas se han realizado investigaciones y análisis en las cuales se han descubierto que la mujer posee rasgos de liderazgo, que la diferencian del modo de liderar del hombre, tal como lo muestra Great Place To Work® Colombia, quien llevó a cabo una investigación sobre la percepción de la mujer profesional en el entorno laboral colombiano, comparándola con la percepción de los hombres sobre 5 aspectos referidos a: Autonomía, Vida personal, Equidad en la remuneración, Justicia en el trato y Ausencia de favoritismo. Arrojando ciertos resultados como: respecto a la autonomía En aspectos como la autonomía y el empoderamiento, la percepción de las mujeres muestra un grado de sensibilidad alto, puesto que han ganado confianza en el desarrollo de sus capacidades y competencias en el entorno laboral, esto agudiza su sentido crítico frente a la supervisión constante del trabajo, en el aspecto de vida personal, se asume que, si bien los cambios estructurales en la cultura, han evidenciado una nueva perspectiva de crecimiento personal y profesional para las mujeres, desplazándolas de un ámbito familiar, aparentemente simple, a uno especializado y con diversos 
enfoques de progreso; las profesionales han incursionado a este contexto con condiciones menos favorables, en la mayoría de los aspectos, en comparación con los hombres, en otro factor como la equidad en la remuneración se muestra que ,esta puede categorizarse como un tema álgido y de alta visibilidad, y esto permite que las comparaciones entre género se evidencian con una brecha relativamente alta.

Las nuevas realidades que nos arropa no son ajenas a la mujer, está a demostrado tener los requisitos habilidades y capacidades para ejercer un cargo de la alta gerencia, y no solo eso, sino en una activa participación y presencia en cargos que catalogaban exclusivos para hombres.

En el transcurso de la investigación hemos encontrado, otras investigaciones que sirven como referencia para nuestro proyecto investigativo, como lo es la indagación realizada por Olga Pizarro y Massiel Guerra, para la Universidad Del Desarrollo, titulada Rol de La Mujer en la Gran Empresa, realizada en Chile a las mujeres emprendedoras donde compartimos la perspectiva que le dan a la desigualdad de género, respecto a dirección de altos cargos directivos, donde indica que "Cabe señalar que la desigualdad de la participación de sexos en cargos de alta dirección se transforma en un problema, cuando existe impedimento para el desarrollo de conductas y deseos legítimos, comúnmente asociados a patrones sociales, culturales y simbólicos y no a una diferencia en términos de preferencias de los individuos. Si las mujeres, por el sólo hecho de su condición, se sienten impedidas para llevar a cabo dichas preferencias, entonces existe un problema de índole social y económico, que se traduce en la pérdida del potencial valioso, que, en este caso, se refleja en pérdida de capital humano en el mercado laboral y en particular, en el ámbito de la dirección. En este sentido, cuando se aspira a una igualdad de género, en realidad se refiere a un estado de desarrollo social en el cual "los derechos, responsabilidades y oportunidades individuales no están determinadas por haber nacido hombre o mujer".

Asimismo, identificamos ejemplos de liderazgo Femenino, en otros países como en el Reino Unido, donde se encuentra Margaret Thatcher, donde Meryl Streep, quien la personifica en la película la "Dama de hierro" revela que, "Ella no podía permitirse ni la risa ni las lágrimas porque sabía que eso sería percibido como una señal de debilidad. También manipuló su voz, su acento, su tono, para convertirse en líder. La falta de sentimientos que siempre se le ha achacado ya la mostraba cuando era 
una joven política. Era muy importante reflejar bien las manifestaciones de aquella personalidad porque tienen mucho que ver con la percepción que se tiene de ella: su grandiosidad, su presencia, la majestuosidad que imprimía a sus opiniones. Hasta ahora percibían de ella dos imágenes totalmente enfrentadas y exageradas: la del ícono y la del monstruo".

Según el artículo, La Mujer Profesional en el Entorno del Trabajo en Colombia, revela que Estudios recientes han demostrado que el $60 \%$ de la población egresada profesional corresponde al género femenino, e incluso carreras que han sido enmarcadas en un rol masculino son el principal foco de interés de este grupo. Hoy, las mujeres profesionales podrían tener mayores oportunidades en los distintos roles de la dinámica empresarial. Su sensibilidad frente al tema de trato justo y equidad está apoyada en las fuertes iniciativas adoptadas por algunos países, como Francia, Holanda, Bélgica e Italia, que se han unido para minimizar la discriminación y posicionar el género en el mercado. La estrategia consiste en aumentar un 30\% la participación de las mujeres para el 2015 y un $40 \%$ para el 2020.

Además de acuerdo con este artículo en América Latina, se encuentran diversos casos de superación del "techo de cristal", siendo Chile el país con más mujeres en altos cargos directivos, con 25\%, según concluyó el lnternational Business Report (IBR) 2011 de la consultora Grant Thornton. Más atrás se ubican Brasil, con 24\%; México, con 19\%, y Argentina, donde ellas sólo ocupan el 18\% de los puestos de alta dirección.

Existe diversa información documental, que es pertinente y relevante estudiar, dado que permiten reconocer el panorama global, referente a la inserción laboral de la mujer en los altos cargos directivos, lo que enfatiza que en diversos países han adoptado la idea, de poner al frente de las organizaciones al género femenino por diversas razones y actualmente las entidades han visto como necesario instaurar políticas incluyentes para conservar el talento femenino.

Se reconoce que la discriminación es un tema muy amplio y de interés abordado en muchas investigaciones realizadas, debido a su aplicabilidad a los diversos campos de la sociedad ya sea de índole religiosa, cultural, ideológica, racial, étnica e incluso hasta de la misma apariencia física, sin omitir la latente discriminación de género. Por tanto, se referenciaron investigaciones del tópico 
central; inserción laboral de las mujeres en los altos cargos directivos, en organizaciones empresariales; tales como:

- "El País - España, informe de la OCDE, - Ellas tienen más estudio y ellos, más trabajo, 2015"

Este estudio realizado en España por la OCDE demuestra la brecha salarial existe entre hombre y mujeres, mostrando también porcentualmente que a pesar de los estudios y nivel de preparación son las menos contratadas en los países que conforman dicha organización, resaltando así que "ellas tienen más estudio y ellos, más trabajo"

Esto alimenta tanto nuestro marco teórico como nuestro planteamiento pues los resultados y conclusiones de este estudio pueden ser utilizados como base en los mencionados anteriormente.

- El Rol de la Mujer en la Administración de las Empresas Manufactureras de la Zona Industrial de Mamonal de la Ciudad de Cartagena en el Periodo Comprendido entre 1995 al 2000. Facultad de Ciencias Económicas, Universidad de Cartagena (trabajo de grado), Julia Lambis Parabuena y Ceveriano Villarraga Caucali. 2002

Este trabajo constituye una fuente de información viable, tomaremos específicamente la justificación que constituye una base angular para el desarrollo de nuestra investigación, pues aclara el desarrollo que ha mostrado la mujer a través del tiempo en el mundo laboral, las capacidades que ha logrado demostrar en los diferentes cargos además de que se busca demostrar que la mujer esta apta para ejercer de igual o mejor forma cargos gerenciales que los hombres.

Lo que se encuentra a fin con nuestra investigación; además que sus postulados, su marco referencial y su marco teórico resultan una fuente importante para la construcción| de nuestra investigación.

- La Orientación de las Mujeres Frente al Empleo: estudio comparativo entre los perfiles ofertados y demandados en el mercado laboral, tesis doctoral, autores: Gil Galván y María del Rosario, 
directores de tesis: Alvares Rojo, Víctor Benedito, Universidad de Sevilla, España, 08 de enero del 2003

Esta tesis doctoral, nos aporta mucho sobre todo en su marco teórico haciendo referencia a la discriminación de la mujer en el ámbito laboral, describiendo y clasificando 21 factores características de la discriminación por razón de sexo; su método deductivo que tomamos muy en cuenta debido a que nuestra investigación también posee este carácter, específicamente hablando, describiendo el problema desde el ámbito internacional, nacional-regional, además los más relevantes datos expuestos en la conclusión de carácter tanto cualitativos como cuantitativos.

- Factores Determinantes en el Posicionamiento de la Mujer en Cargos Directivos en el Sector Financiero de la Ciudad de Cartagena, trabajo de grado, administración de empresas, Universidad de Cartagena, Mónica Patricia Pérez Orozco, Tatiana Patricia Ávila Ávila, 2009.

Esta investigación es importante para contextualizar nuestro tema de estudio, además que ayuda a aterrizar la investigación, en la ciudad de Cartagena y posee datos específicos que abordan soluciones a los ejes interrogativos de nuestro planteamiento, lo cual enfoca más claridosamente el curso de la investigación, pues destaca la importancia de identificar los factores que han generado la participación de la mujer en altos cargos, en las organizaciones empresariales, de la ciudad Cartagena de Indias.

- Determinantes de la Participación Femenina en el Mercado Laboral: caso Cartagena, trabajo de grado, facultad de economía, Universidad de Cartagena, Nallydis Hernández Miranda, 2011

Arroja información valiosa, sobre el establecimiento de la mujer en el mercado laboral Cartagenero, representando ítems claves que son definitivos en nuestro proyecto de investigación, este proyecto formula enunciados equivalentes a componentes que están siendo estudiados como determinantes en la influencia de nuestro tema investigativo, sirviendo la argumentación de su hipótesis general y específica como punto de solución a la problemática de los diversos factores que obstaculizan la inserción de la mujer en el mercado laboral. 
- Participación de Mujeres en Cargos Gerenciales: una investigación cualitativa de empresas financieras (seminario), Facultad de Economía y Negocios, Universidad de Chile, Fanny Gallegos Pereira, Javiera Guzmán Garrido, Camila Saavedra cubillos, Andrea Silva Hidalgo. 2012

Estudios realizados en la Universidad de chile, denotan como objetivo principal lograr saber cuáles son aquellas principales barreras $\mathrm{u}$ obstáculos que enfrenta la mujer en cargos medios para incursionarse a altos cargos gerenciales en el sector financiero abordando su impacto en distintos ambientes como el familiar, el organizacional y el personal o individual y su respectivo desenvolvimiento.

Todo el estudio realizado tiene información y resultados que son muy importantes y verídicos, sin embargo de este trabajo nosotros acogemos el ítem de recomendaciones para futuros estudios en el hecho de que nos parecería interesante realizar un análisis abarcando un estudio más allá de la visión del hombre o incorporando una visión masculina al estudio como tal, para así lograr darle otro enfoque de tal manera que podamos evaluar desde una vista más amplia todo este proceso de ascensión de la mujer en altos cargos gerenciales.

- Seminario Permanente de Ciencias Sociales: "Mobbing y Otros Obstáculos para el Desarrollo Laboral de las Mujeres, Universidad de Castilla-la Mancha, España Faculta de Ciencias Sociales de Cuenca, i.s.s.n.: 1887-3464 (ed. cd-rom) 1988-1118 (ed. en línea) d.1.: cu-532-2005, impreso en España, autor: Brenda Fabiola Chávez Bermúdez, dra. en derecho, profesora-investigadora del instituto de investigaciones jurídicas de la Universidad Juárez del estado de Durango, México; año 2012

En este seminario nos aporta mucho en su introducción (pag:5-7) donde podemos darnos cuenta de aquellas posibles causas del bajo desarrollo de la mujer en el campo laboral como lo es el "Mobbing" o acoso moral que en algunos casos también podría ser "Mobbing” Maternal (discriminación de la féminas debido a su estado de embarazo)y otras causas que se desarrollan a lo largo de la investigación; que pueden ser de gran ayuda al momento de desarrollar nuestro planteamiento del problema, por otro lado sus conclusiones y propuestas (pag:18-20) enfocadas a dar una solución para aumentar y dinamizar la demanda de mujeres en el mercado laboral. 
Las nuevas realidades que nos arropa no son ajenas a la mujer, ésta ha demostrado tener los requisitos habilidades y capacidades para ejercer un cargo de la alta gerencia, y no solo eso, sino en una activa participación y presencia en cargos que catalogaban exclusivos para hombres. Este hecho lo podemos presenciar en un estudio realizado por El País (2011), donde demuestra dicha participación aterrizando en el sector bancario, en Colombia, reflejado en el mes de mayo y julio de 2011, 131.000 mujeres hacían parte de este sector mientras que 105.000 representaba la presencia masculina en este sector, marcada tal diferencia se puede presenciar que el género femenino está cada vez pisando más fuerte en terrenos que antes parecían inasequibles.

Se puede afirmar, que las mujeres cada vez se están abriendo campo en distintas áreas, “Hoy no debe haber discriminación en los sectores laborales, si bien hay áreas como la ingeniería mecánica en donde ellos son más, las mujeres tienden a buscar cabida allí. Y en el sector administrativo y financiero encontramos más mujeres laborando”, explicó Ramírez. (El País, 2011).

\section{Diseño metodológico}

Este proceso metodológico se constituye en un estudio de casos, donde se escoge a la Dra. Roxana Segovia de Cabrales, que en el momento se encontraba como rectora de la Universidad Jorge Tadeo Lozano-Seccional Caribe quien se constituye de manera inmediata en nuestro objeto de estudio, lo que nos permite incursionar en el método de caso. Ahora bien, este proceso se encuentra en la fase exploratoria de la segunda fase del mismo, el cual se llevará a cabo mediante un diseño descriptivocorrelacional, buscando así ampliar nuestro objeto de estudio hacia el sector financiero de la ciudad de Cartagena. Descriptiva ya que se busca encontrar y medir, los diferentes factores determinantes, para que la mujer, incursione en el mercado laboral, específicamente en altos cargos directivos en las entidades financieras Colombiana, puntualmente en la ciudad de Cartagena; Correlacional, ya que pretendemos relacionar las variables, dependientes e independientes, que intervienen, en el proceso de inserción laboral, ascenso y posicionamiento de la mujer, como dirigentes del organigrama, en una entidad financiera

La temática a tratar en el proyecto abordará de manera cualitativa, las variables relacionadas, que permiten comprender los factores socioculturales, estereotipos, paradigmas, problemáticas políticas, 
que inciden en el momento de la mujer liderar el aparato organizacional de una entidad financiera, del mismo modo, llegar a evaluar su desempeño y niveles de rendimiento en el cargo.

Ahora bien, en la primera fase proyectando un enfoque cualitativo, tomando como bases hechos observables y teorías, nexo a esto se usó la entrevista abierta como técnica, la cual permitió la obtención de la información necesaria para entonces analizar nuestro objeto de estudio, mediante el cual nos manifestó unas variables tales como:

- Variables Dependientes: Inserción Laboral (Y) - Retribución Salarial (Y')

- Variable Independiente: Educación y/o Formación Académica (X)

- Variable de Control: Ascenso de Cargo (Xc)

- Variable Moderador: Género (Xm)

- Variable Interviniente: Techo de Cristal (Xi)

Tabla 1. Variables

\begin{tabular}{|c|c|c|c|c|c|}
\hline Variables & Concepto & Dimensión & Definición & Pregunta & Fuente \\
\hline \multirow{2}{*}{$\begin{array}{l}\text { Inserción } \\
\text { Laboral }\end{array}$} & \multirow{2}{*}{$\begin{array}{l}\text { Es una acción que } \\
\text { pretende incorporar e } \\
\text { incluir al sector } \\
\text { laboral, a todas las } \\
\text { personas que, por } \\
\text { diferentes motivos y } \\
\text { situaciones, son } \\
\text { excluidas de este } \\
\text { ámbito }\end{array}$} & INCORPORAR & $\begin{array}{l}\text { Involucrar a la } \\
\text { mujer en el } \\
\text { mercado laboral } \\
\text { en altos cargos } \\
\text { directivos. }\end{array}$ & \multirow{2}{*}{$\begin{array}{l}\text { ¿Desde cuándo } \\
\text { visualizó el } \\
\text { hecho de la } \\
\text { inserción } \\
\text { laboral, como un } \\
\text { aspecto } \\
\text { primordial en su } \\
\text { vida? ¿Lo atribuye } \\
\text { ¿Lomo un hecho } \\
\text { rascendental si } \\
\text { es así, por qué? } \\
\end{array}$} & \multirow{2}{*}{$\begin{array}{c}\text { Entrevista } \\
\text { Abierta }\end{array}$} \\
\hline & & EXCLUSION & $\begin{array}{l}\text { Discriminar a la } \\
\text { mujer en el } \\
\text { ámbito laboral. }\end{array}$ & & \\
\hline \multirow{2}{*}{$\begin{array}{c}\text { Retribución } \\
\text { Salarial }\end{array}$} & \multirow{2}{*}{$\begin{array}{c}\text { Son aquellas } \\
\text { cantidades abonadas } \\
\text { al trabajador por el } \\
\text { trabajo efectivamente } \\
\text { realizado }\end{array}$} & TRABAJO & $\begin{array}{l}\text { Desempeño de } \\
\text { sus roles y cargos } \\
\text { dentro de la } \\
\text { organización. }\end{array}$ & \multirow{2}{*}{$\begin{array}{l}\text { ¿Su retribución } \\
\text { salarial la cree } \\
\text { acorde para el } \\
\text { desempeño } \\
\text { directo con } \\
\text { cargo su } \\
\text { ocupa? }\end{array}$} & \multirow{2}{*}{$\begin{array}{c}\text { Entrevista } \\
\text { Abierta }\end{array}$} \\
\hline & & EFECTIVIDAD & $\begin{array}{l}\text { Capacidad para } \\
\text { realizar su trabajo } \\
\text { de manera que } \\
\text { pueda alcanzar su } \\
\text { objetivo. }\end{array}$ & & \\
\hline
\end{tabular}




\begin{tabular}{|c|c|c|c|c|c|}
\hline \multirow{3}{*}{$\begin{array}{l}\text { Educación- } \\
\text { Formación } \\
\text { Académica }\end{array}$} & \multirow{3}{*}{$\begin{array}{l}\text { La formación } \\
\text { académica es un } \\
\text { conjunto de } \\
\text { conocimientos } \\
\text { adquiridos, los cuales } \\
\text { son una herramienta } \\
\text { que te ayudarán a } \\
\text { consolidar las } \\
\text { competencias que } \\
\text { posees. }\end{array}$} & $\begin{array}{l}\text { FORMACION } \\
\text { ACADEMICA }\end{array}$ & $\begin{array}{l}\text { Grado o nivel de } \\
\text { educación } \\
\text { alcanzado por la } \\
\text { mujer. }\end{array}$ & \multirow{3}{*}{$\begin{array}{l}\text { ¿Cuán } \\
\text { primordial, ha } \\
\text { sido } \\
\text { formación } \\
\text { académica para } \\
\text { la vinculación } \\
\text { del cargo de } \\
\text { rectora? }\end{array}$} & \multirow{3}{*}{$\begin{array}{c}\text { Entrevista } \\
\text { Abierta }\end{array}$} \\
\hline & & CONOCIMIENTO & $\begin{array}{c}\text { Conjunto de } \\
\text { saberes y } \\
\text { aptitudes que } \\
\text { ayudan a ser apta } \\
\text { para un cargo } \\
\text { dentro de la } \\
\text { organización. } \\
\end{array}$ & & \\
\hline & & COMPETENCIAS & $\begin{array}{c}\text { Habilidades } \\
\text { propias para } \\
\text { desempeñar } \\
\text { alguna actividad } \\
\text { laboral. }\end{array}$ & & \\
\hline
\end{tabular}

continua

\begin{tabular}{|c|c|c|c|c|c|}
\hline \multirow{2}{*}{$\begin{array}{l}\text { Ascenso } \\
\text { de } \\
\text { Cargo }\end{array}$} & \multirow{2}{*}{$\begin{array}{l}\text { Es el Progreso en } \\
\text { materia de } \\
\text { categoría, posición, } \\
\text { que alguien } \\
\text { consigue a } \\
\text { instancias de su } \\
\text { empleo }\end{array}$} & PROGRESO & $\begin{array}{l}\text { Grado de avance } \\
\text { que le permite a la } \\
\text { mujer escalar los } \\
\text { cargos laborales. }\end{array}$ & \multirow{2}{*}{$\begin{array}{l}\text { ¿Qué habilidades } \\
\text { considera usted al } \\
\text { momento de ascender } \\
\text { a un trabajador, toma } \\
\text { como pre requisito su } \\
\text { género? }\end{array}$} & \multirow{2}{*}{$\begin{array}{c}\text { Entrevista } \\
\text { Abierta }\end{array}$} \\
\hline & & POSICION & $\begin{array}{l}\text { Status que } \\
\text { produce mayor } \\
\text { autoridad y } \\
\text { responsabilidad } \\
\text { disponibilidad de } \\
\text { subordinados. }\end{array}$ & & \\
\hline \multirow{2}{*}{ Genero } & \multirow{2}{*}{$\begin{array}{c}\text { conjunto de } \\
\text { características } \\
\text { diferenciadas que } \\
\text { cada } \\
\text { sociedad asigna a } \\
\text { hombres y mujeres }\end{array}$} & DIFERENCIACION & $\begin{array}{l}\text { Desigualdad e } \\
\text { inequidad con } \\
\text { relación a los } \\
\text { salarios entre } \\
\text { hombres y } \\
\text { mujeres. } \\
\end{array}$ & \multirow{2}{*}{$\begin{array}{l}\text { ¿Qué tan } \\
\text { determinante ha sido } \\
\text { él género, para } \\
\text { ocupar el cargo de } \\
\text { rectora y también } \\
\text { para la asimilación } \\
\text { de sus subordinados? } \\
\text { ¿Teniendo en cuenta } \\
\text { que es primera vez, } \\
\text { que una mujer } \\
\text { desempeña ese rol, } \\
\text { en la universidad? }\end{array}$} & \multirow{2}{*}{$\begin{array}{c}\text { Entevista } \\
\text { Abierta }\end{array}$} \\
\hline & & SOCIEDAD & $\begin{array}{l}\text { Círculo, entorno y } \\
\text { ambiente donde } \\
\text { se fecunda la } \\
\text { discriminación } \\
\text { frente a la mujer. }\end{array}$ & & \\
\hline $\begin{array}{l}\text { "Techo } \\
\text { de } \\
\text { Cristal" }\end{array}$ & $\begin{array}{l}\text { Todas aquellas } \\
\text { problemáticas que } \\
\text { impiden que la } \\
\text { mujer avance de la } \\
\text { base de la pirámide }\end{array}$ & PROBLEMATICAS & $\begin{array}{l}\text { Fenómenos y } \\
\text { falencias que } \\
\text { impiden a la } \\
\text { mujer insertar al } \\
\text { mercado laboral. }\end{array}$ & $\begin{array}{l}\text { ¿En el transcurso de } \\
\text { su desempeño como } \\
\text { rectora, se ha topado } \\
\text { con obstáculos, } \\
\text { menciones cuáles? Si }\end{array}$ & $\begin{array}{c}\text { Entrevista } \\
\text { Abierta }\end{array}$ \\
\hline
\end{tabular}




\begin{tabular}{|c|c|c|c|}
\hline económica & AVANCE & $\begin{array}{l}\text { Imposibilidad de } \\
\text { alcanzar su } \\
\text { desarrollo } \\
\text { intelectual para } \\
\text { obtener altos } \\
\text { cargos } \\
\text { gerenciales. }\end{array}$ & \multirow{2}{*}{$\begin{array}{l}\text { es así ¿Qué tanto han } \\
\text { afectado a qué logre } \\
\text { avanzar con sus } \\
\text { objetivos? }\end{array}$} \\
\hline & OBSTACULOS & $\begin{array}{l}\text { Todas aquellas } \\
\text { barreras que no le } \\
\text { permiten a la } \\
\text { mujer ubicarse en } \\
\text { los altos cargos } \\
\text { gerenciales. }\end{array}$ & \\
\hline
\end{tabular}

Fuente: elaboración propia de los autores

\section{CONCLUSIÓN}

En suma, un análisis de tipo descriptivo nos permitió estudiar las categorías de paradigmas socioculturales, condición de género, formación académica y contribución salarial, las cuales a través de una entrevista abierta, realizada a la Dra. Roxana Segovia, que en su momento sirvió de estudio de casos, para contextualizar nuestra investigación y desde ahí ampliar nuestra percepción de estudio, sabiendo que al ser una entrevista desestructurada, la información fue retomada desde un dialogo abierto donde, el tema principal fue los roles de la mujer en la sociedad, el mercado laboral y la retribución salarial, no solo en los cargos directivos donde se desempeña, sino en los demás cargos donde las féminas, han tomado espacio tras el transcurrir de los tiempos.

Asimismo la evolución de la sociedad ha contribuido al escalonamiento y posicionamiento de la mujer en todos los ámbitos de la vida, por lo cual vinculamos la formación académica como un punto de partida importante para ello, tras la revisión de la información suministrada en este dialogo y así, haciendo comparación con la información de la primera fase del proyecto, la observación, el rastreo de fuentes y documentos pudimos incluir que aunque hoy día, aún existe la tendencia al mercado laboral y la fuerza de trabajo masculina, hay espacios fuertemente influenciados por la mujer, en más proporción que otros, como es el campo educativo, especialmente las universidades, donde las características como: histrionismo, organización, meticulosidad y sobre todo la multifuncionalidad, donde se desempeñan como madres y trabajadoras a la vez, para escalonar laboralmente, el poder y la política son factores determinantes, en cierto modo afecta dado que estos ámbitos, siguen fuertemente 
precedidos por figuras masculinas, por lo que la formación académica resulta determinante, dado que permitirá al género femenino ser más competitivo y apto.

Actualmente en nuestro país las brechas salariales, han disminuido, dado que la selección del personal y la retribución, tiende ser equitativa además proporcional al cargo que ocupa y las habilidad que posee, los paradigmas socioculturales, siguen siendo relevantes dado que categorizan labores para hombre y mujeres; existen leyes y políticas, que favorecen a unos, por su condición de género, la igualdad y la equidad, resultan siendo catalogadas como sinónimos, podemos decir que aunque existe todavía el suelo pegajoso o techo de cristal, hay más inserción de mujeres al mercado laboral, con menos diferenciación en el salario y con más respaldo del Estado que permite, que cada vez exista más equidad.

\section{REFERENCIAS BIBLIOGRAFICAS}

Cárdenas, C., Durana, F. (2009). La particularidad de la ejecutiva colombiana

Castro-Alfaro, A., Mercado-León, L., Gonzalez-Pérez, N. (2016). Responsabilidad social corporativa en cadenas hoteleras: Hotel Las Américas en Cartagena de Indias. Panorama Económico, 24, 283-296. DOI: https://doi.org/10.32997/2463-0470-vol.24-num.0-2016-1563

Clavijo-Vera, S., Vera-Sandoval, A., Vera-Concha, N. (2015). Politica monetaria: reglas y discreción. Panorama Económico, 23: 31-38. DOI: https://doi.org/10.32997/2463-0470-vol.23-num.1$\underline{2015-1375}$

Chavez, B. (2012). Mobbing y otros obstáculos para el desarrollo laboral de las mujeres. Universidad De Castilla-La Mancha, España Faculta De Ciencias Sociales De Cuenca, ISSN: 1887-3464 (Ed. CDROM) 1988-1118 (Ed. En Línea).

Constantinidis, F. (2010). Context, Process and Gender in Entrepreneurship 
De la Hoz, A., Camargo-Montoya, P., Saldarriaga-Arango, C., Praj, D. (2014). Análisis de los riesgos en las importaciones colombianas. Panorama Económico, 22, 63-75. DOI: https://doi.org/10.32997/2463-0470-vol.22-num.0-2014-1360

Eagly \& Carli (2007). Through the labyrinth: The truth about how women become leaders

El País - España. (2015). Informe de la OCDE, - Ellas tienen más estudio y ellos, más trabajo.

El País (2011). Las mujeres dominan hoy el empleo en el sector bancario.

Gallegos-Pereira, F. Guzmán-Garrido, J., Saavedra-Cubillos, C. Silva-Hidalgo, A. (2012). Participación de mujeres en cargos gerenciales: una investigación cualitativa de empresas financieras. Facultad de Economía y Negocios, Universidad de Chile.

Galván, G., Rosario, M. (2003). La orientación de las mujeres frente al empleo: estudio comparativo entre los perfiles ofertados y demandados en el mercado laboral. Tesis Doctoral, Universidad De Sevilla, España.

García-García, F. (2017). Debate sobre la inclusión del cooperativismo dentro de las políticas de la nueva ruralidad en América Latina. Panorama Económico, 25, 3: 357-380 DOI: https://doi.org/10.32997/2463-0470-vol.25-num.3-2017-2081

Great Place To Work (2012). La mujer profesional en el entorno del trabajo en Colombia.

Grimwood y Popplestone (1993). Women, Management and Care

Hernández Miranda, N. (2011). Determinantes de la participación femenina en el mercado laboral: caso Cartagena. Trabajo de Grado, Facultad de Economía, Universidad de Cartagena.

Lambis-Parabuena, J., Villarraga-Caucali, C. (2002). El rol de la mujer en la administración de las empresas manufactureras de la zona industrial de Mamonal de la ciudad de Cartagena en el periodo 
comprendido entre 1995 al 2000. Facultad de Ciencias Económicas, Universidad de Cartagena (Trabajo de Grado).

Lipman-Blumen, D. (2000). Leadership in a changing world.

Mora, Fritz y Valdés (2006). Igualdad y equidad de género: aproximación teórico-conceptual

Mujer Y Poder: Representaciones Sociales. Caso De Beatriz Bechara De Borge, Primera Rectora De La Universidad De Cartagena 1988-1990.

Passos-Simancas, E., Arias-Aragones, F. (2016). El capital humano como factor de competitividad en la industria hotelera y turística en Cartagena. Panorama Económico, 24, 269-282. DOI: https://doi.org/10.32997/2463-0470-vol.24-num.0-2016-1561

Perez Orozco, M, Ávila, T. (2009). Factores determinantes en el posicionamiento de la mujer en cargos directivos en el sector financiero de la ciudad de Cartagena. Trabajo de Grado, Administración de Empresas, Universidad de Cartagena

Pizarro S., Massiel Guerra G. (2010). Rol de la mujer en la gran empresa, un estudio del programa chile emprendedoras.

Razavi \& Miller, 1995; From WID to GAD: Conceptual Shifts in the Women and Development Discourse

Salazar-Mosquera, G. (2017). Factores determinantes del desempeño financiero en el sector manufacturero en la República del Ecuador. Panorama Económico, 25, 2: 243-254. DOI: https://doi.org/10.32997/2463-0470-vol.25-num.2-2017-2076 